\title{
Production of Infant Formula Analogs by Membrane Fractionation of Caprine Milk: Effect of Temperature Treatment on Membrane Performance
}

\author{
Catherine O. Maduko ${ }^{1}$, Young W. Park ${ }^{1,2^{*}}$ \\ ${ }^{1}$ Department of Food Science and Technology, The University of Georgia, Athens, USA; ${ }^{2}$ Georgia Small Ruminant Research \& Ex- \\ tension Center, Fort Valley State University, Fort Valley, USA. \\ Email: "parky@fvsu.edu
}

Received August $3^{\text {rd }}$, 2011; revised November $17^{\text {th }}, 2011$; accepted November $26^{\text {th }}, 2011$.

\begin{abstract}
A two-step-cascade membrane separation by ultrafiltration was performed on caprine milk prepared under different temperature conditions to eliminate beta-lactoglobulin $(\beta-L g)$ from the whey fraction. Effects of temperature treatment and membrane pore size on the elimination of $\beta$ - Lg and retention of alpha-lactalbumin $(\alpha-L a)$ were examined to determine the optimum permeate fraction for production of infant formula analogues from caprine milk. The frozen raw caprine milk, with and without prior pasteurization, showed the best membrane separation performance. The permeates obtained from the 800/30 kDa membrane combination showed the optimal results. The infant formula analog produced using the casein and 800/30 kDa-permeate fractions of the treated caprine milk had the closest similarity to human milk with respect to the total protein content $(1.3 \mathrm{~g} / 100 \mathrm{~g})$, beta-lactoglobulin content $(1 \%-2 \%)$, and casein- $\alpha$-lactalbumin ratio (0.6 - 0.7). Membrane performance during ultrafiltration of caprine milk was affected by temperature treatment of the milk prior to membrane separation.
\end{abstract}

Keywords: Caprine Milk, Membrane Fractionation, Temperature Effect, Infant Formula Analogue

\section{Introduction}

Caprine milk has been recommended as a good substitute for bovine milk, and has become a more popular alternative base milk for the feeding of infants who cannot be breast-fed, and especially for infants with allergies to bovine milk [1-3]. Caprine milk is reportedly less allergenic and more digestible than bovine milk [2,4-6].

Various reports also has shown that caprine milk is different from bovine or human milk with higher digestibility, distinct alkalinity, higher buffering capacity, and therapeutic values in human nutrition and medicine [1, 7-10]. Virtually all infants who are allergic to bovine milk can tolerate caprine milk [2,11]. These infants may have been sensitive to bovine $\alpha$-lactalbumin, which is species-specific, and beta-lactoglobulin $(\beta$-Lg), which is mostly responsible for bovine milk allergy. $\beta$ - $\mathrm{Lg}$ is a milk protein that is highly resistant to intestinal luminal hydrolysis and mostly responsible for milk allergy [12]. This protein is a major whey protein in bovine milk, which is completely lacking in human milk [2,3]. Caprine milk contains lower levels of $\beta$-Lg than bovine milk, and milk of some dairy goat breeds have little or no $\beta$-Lg [13].

Caprine milk differs from human milk in both total protein content and casein/lactalbumin ratio, and the protein energy ratio of whole caprine milk is too high for its use as an infant food [13,14]. The physical characteristics of the major caprine milk proteins are shown in Table 1. Caprine milk $\beta$-Lg, like its bovine milk homolog, consists of a polypeptide chain of 162 amino acid residues [3,15], and has 3 fewer negatively charged and one more positively charged residues than bovine milk $\beta$ - $\mathrm{Lg}$ at $\mathrm{pH}$ values of 5 to 9 . The removal of $\beta$ - $\mathrm{Lg}$ from caprine milk is difficult due to its $\mathrm{pH}$ dependency in the complex biological fluid system [3]. $\alpha$-La, on the other hand, is a predominant whey protein in human milk, and consists of about of $30 \%$ of the whey proteins in caprine milk [13]. Elimination of $\beta$-Lg from caprine milk while 
Table 1. Physical characteristics of the major whey proteins in goat milk.

\begin{tabular}{ccc}
\hline Protein & $\begin{array}{c}\text { Concentration } \\
(\mathrm{g} / 100 \mathrm{~g})\end{array}$ & $\begin{array}{c}\text { Molecular weight } \\
\left(\mathrm{g} \cdot \mathrm{mol}^{-1}\right)\end{array}$ \\
\hline Beta-lactoglobulin & 0.27 & 18,362 \\
Alpha-lactalbumin & 0.12 & 14,147 \\
Immunoglobulin & 0.065 & $150,000-1,000,000$ \\
Serum albumin & 0.04 & 69,000 \\
Lactoferrin & 0.01 & 78,000 \\
Lactoperoxidase & 0.002 & 7000 \\
\hline
\end{tabular}

Data from Wong et al. (1996); Cayot and Lorient (1997); Park (2006).

retaining alpha-lactalbumin is therefore one step toward humanizing the protein composition of caprine milk for infant feeding.

Most previous studies of milk fractionation have focused on salt/acid precipitation, ion exchange and affinity chromatography systems for selective protein purification. However, these systems have unacceptable economies at large scale $[16,17]$, and require changes in the $\mathrm{pH}$ of the native milk system [18] which might make the milk unacceptable for use in infant milk formulation. Membrane processes are used extensively throughout the dairy industry because they can be effectively and economically implemented at the large scale required for most dairy applications $[17,19]$.

Temperature treatment is widely used to modify the properties of milk and milk products. The main change that occurs during temperature treatment of milk is denaturation of the milk proteins, which may cause a simultaneous change in permeate flux during subsequent membrane processing of the milk [19]. Almost no studies have been reported on the modification of caprine milk proteins by membrane fractionation based on molecular size and temperature treatment to eliminate $\beta$-Lg while retaining $\alpha$-La for infant feeding. The objectives of this study, therefore, were: 1 ) to lower the $\beta$-Lg and casein/ whey protein ratio of caprine milk without change in normal milk $\mathrm{pH}$ to simulate human milk protein composition; and 2) to determine the effect of temperature treatment on the separation performance of caprine milk protein by ultrafiltration.

\section{Materials and Methods}

\subsection{Preparation of Materials}

\subsubsection{Protein Standards, Chemicals and Membranes}

Standard proteins of $\beta$-Lg and $\alpha$-La were obtained from Sigma-Aldrich (St. Louis, MO, USA). Water (HPLCgrade) was purchased from Fisher Scientific (Fair Lawn,
NJ, USA). All other chemicals used were of analytical and chromatographic grade. Polyethersulfone membrane flat sheets of $800,30,10$, and $5 \mathrm{kDa}$ molecular weight cut-off series were purchased from Synder filtrations (Vacaville, CA, USA). The membrane flat sheets were equilibrated with reverse-osmosis (RO) water and operable in $\mathrm{pH}$ range of 1 - 14. Membranes were also compatible with both organic and aqueous media, were cleaned with RO water, nitric acid, alkali detergent (klenzade; Sigma-Aldrich, St. Louis, MO, USA) and could be preserved in sodium metabisulfite.

\subsubsection{Caprine Milk Samples}

Raw caprine milk was obtained from the bulk tank milk of late lactation Saanen, Nubian, and Alpine dairy goat breeds at the Georgia Small Ruminant Research and Extension Center, Fort Valley State University (Fort Valley, Georgia). The average daily milk yield was $0.5 \mathrm{~L}$ per head and the average somatic cell count of the milk was 550,000 cells $\cdot \mathrm{mL}^{-1}$. The goats were fed Bermuda grass hay ad libitum, and $0.45 \mathrm{~kg}$ of concentrate twice daily. The concentrate contained $5.0 \%$ of crude fat and $2.72 \%$ of digestible energy, which ensured $17 \%$ of fiber in the total diet. The raw caprine milk were collected at two separate times from the same bulk tank stored at $4^{\circ} \mathrm{C}$.

\subsection{Experimental Design}

\subsubsection{Temperature Treatments of Caprine Milk}

The raw caprine milk was subjected to temperature treatments. One batch was treated as raw milk, and the other batch was immediately pasteurized at $63^{\circ} \mathrm{C}$ for 30 min after collection. Both batches of the caprine milk were divided into two equal portions. One part was immediately refrigerated at $4^{\circ} \mathrm{C}$, and the other part was immediately frozen and stored at $-35^{\circ} \mathrm{C}$, which gave the following temperature treated milk samples: RGM (raw, refrigerated goat milk); FGM (raw, frozen goat milk); PGM (pasteurized, refrigerated goat milk); and PFGM (pasteurized, frozen goat milk). Thereafter, the four treated caprine milk samples and fresh caprine milk as a control were tempered overnight at $4^{\circ} \mathrm{C}$. After the temperature treatments, fats were separated (skimmed) from all treated whole caprine milk using a cream separator (Armfield FT15, Armfield, London, UK) for protein formulations through ultrafiltration processes. This temperature treatment experiments were conducted in two replicates.

\subsubsection{Ultrafiltration Treatments of Caprine Milk}

Protein separation of the temperature treated milks was carried out in a batch ultrafiltration unit (NIRO Lab20, Hudson, WI, USA), containing a fixed disc module (DOW, Denmark). The ultrafiltration unit was equipped 
with 76-mm radius flat disks, a diaphragm circulation pump, a shell, and tube heat-exchanger. Inlet pressure of the feed was maintained at 30 psi (pressure $2.54 / \mathrm{cm}^{2}$ ) maximum, while outlet flow rate was maintained at 500 $\mathrm{mL} \cdot \mathrm{min}^{-1}$. The back-pressure valve was used to maintain the outlet flow rate.

Fractionation of the temperature treated milks was performed by ultrafiltration in two steps using different membrane pore sizes (two-step-cascade). First-step fractionation was done with the 800 and $30 \mathrm{kDa}$ molecular weight cut-off membranes, using the flat disks of $76 \mathrm{~mm}$ actual radii and $56 \mathrm{~mm}$ effective radii. Milk samples were run through the ultrafiltration system until a 3x retention factor was obtained for all retentates. The retentates obtained from this first fractionation were regarded as caseins, while permeates obtained were individually used as the feed for further fractionation.

The second-step fractionation was carried out with the 30,10 , and $5 \mathrm{kDa}$ molecular weight cut-off membranes. The retentate and permeate milk fractions obtained were then labeled as: $800 \mathrm{kD}-$ ret: $800 \mathrm{kDa}$ retentate fraction; 800/30-per: 800/30 kDa permeate fraction; 800/10-per: 800/10 kDa permeate fraction; 800/5-per: $800 / 5 \mathrm{kDa}$ permeate fraction; $30 \mathrm{kD}$-ret: $30 \mathrm{kDa}$ retentate fraction; 30/10-per: 30/10 kDa permeate fraction; 30/5-per: 30/5 $\mathrm{kDa}$ permeate fraction.

The skimmed fresh goat milk (SGM), and all fractions from the temperature treated milks were collected separately in flat pyrex dishes $(200 \mathrm{~mm} \times 150 \mathrm{~mm} \times 20 \mathrm{~mm})$ and frozen overnight at $-40^{\circ} \mathrm{C}$. Thereafter, the samples were lyophilized using a freeze-drier (VirTis Freeze Mobile25, VirTis, Gardiner, NY, USA) at a pressure of 133 $\times 10^{-4} \mathrm{kPa}$ and temperature of $-40^{\circ} \mathrm{C} \pm 2^{\circ} \mathrm{C}$. The samples were then stored as lyophilisates in Styrofoam containers at $-40^{\circ} \mathrm{C} \pm 2^{\circ} \mathrm{C}$, until needed for further analysis. Ultrafiltration experiment was performed in duplicates for each treatment groups, resulting in four replicates per each temperature treatment group.

\subsubsection{Formulations of Infant Formula Analogs}

The casein fraction of each milk sample was diluted to normal strength (3x dilution) with RO water. Optimum permeate fraction was chosen by determining the permeate with the highest percentage $\beta$-Lg elimination and $\alpha$-La retention. Four different types of infant formulas were then prepared by combining one part of the diluted casein fraction (from the first-step fractionation) and four parts of the corresponding optimum permeate fractions $\left(\mathrm{v} \cdot \mathrm{v}^{-1}\right)$ obtained from each of the treated milk samples after the second-step fractionation. The prepared infant formula analogs were then lyophilized, and stored in a freezer as described above until further chemical analysis.
Formulation of infant formula analogs was performed in duplicates for each treatment groups, resulting in four replicates per each treatment group from the two separate experiments.

\subsection{Chemical Analysis}

\subsection{1. pH and Total Protein Assays}

The $\mathrm{pH}$ of SGM, infant formula analogs, and milk fractions were determined using a pH-meter (Fisher Scientific, AR10, Fair Lawn, NJ, USA). Prior to analysis, lyophilisates were reconstituted by mixing them with RO water at a ratio of 12.5:87.5 $\left(\mathrm{w}^{\cdot} \cdot \mathrm{v}^{-1}\right)$.

Total protein content of the infant formula analogs was determined by total nitrogen assay using the Perkin Elmer 2400 Series II CHNS/O Analyzer (Covina, CA, USA). Total nitrogen content was multiplied by a factor of 6.38 to give the total protein content.

\subsubsection{HPLC Analysis}

Analysis of the milk fraction samples was conducted by the HPLC method described by Kuwata et al. [18], using a Hewlett Packard (Series II 3247A) model 1090 M (Ramsey, MN, USA) equipped with a 1046A UV/VIS detector. Lyophilized samples were reconstituted by mixing with RO water at the rate of $12.5: 87.5\left(\mathrm{w}^{\cdot} \cdot \mathrm{v}^{-1}\right)$. Protein separation was carried out on a Bio-Sil SEC 125 - 5 column $(300 \times 7.8$ mm) (Bio Rad Co., Richmond, CA, USA) coupled with a Bio-Sil SEC 125 guard column (80 $\times 7.8 \mathrm{~mm}$ ). The mobile phase was $0.05 \mathrm{M}$ phosphate buffer ( $\mathrm{pH}$ 6.0) containing $0.2 \mathrm{M}$ sodium sulfate and $0.02 \%$ sodium azide. The flow rate was $1 \mathrm{~mL} \cdot \mathrm{min}^{-1}$, and the eluents were monitored by measuring the absorbance at $225 \mathrm{~nm}$ or at $280 \mathrm{~nm}$.

\subsection{Statistical Analysis}

All experimental data collected from the 4 prepared infant formula analogues were statistically analyzed by analysis of variance, Duncan's multiple means comparison, and least squares mean comparison among different treatments with reference to the reported human milk composition, using the general linear model (GLM) of SAS program [20].

\section{Results and Discussion}

\subsection{The pH Values}

The $\mathrm{pH}$ values of the four types of infant formula analogs for the whole milk, caseins and different fractions obtained by ultrafiltration fractionation of the caprine milk are given in Table 2. The range of $\mathrm{pH}$ for all samples was $6.2-6.5$, which is close to the $\mathrm{pH}$ of human milk ( 6.3). All milk fractions had similar $\mathrm{pH}$ values to their corresponding base milk, and there was no significant 
Table 2. Comparison of pH values among different temperature treatment groups and milk fractions relative to human milk.

\begin{tabular}{|c|c|c|c|c|c|}
\hline \multirow{2}{*}{ Fractions } & \multicolumn{5}{|c|}{$\mathrm{pH}$} \\
\hline & RGM & PGM & FGM & PFGM & $\mathrm{HM}^{\mathrm{a}}$ \\
\hline Whole milk & $6.51 \pm 0.1$ & $6.51 \pm 0.1$ & $6.51 \pm 0.1$ & $6.51 \pm 0.1$ & $6.25-6.29$ \\
\hline Caseins & $6.52 \pm 0.1$ & $6.50 \pm 0.1$ & $6.51 \pm 0.2$ & $6.49 \pm 0.2$ & - \\
\hline 800 kD-ret & $6.28 \pm 0.0$ & $6.29 \pm 0.2$ & $6.28 \pm 0.1$ & $6.30 \pm 0.1$ & - \\
\hline 800/30-per & $6.29 \pm 0.0$ & $6.29 \pm 0.1$ & $6.30 \pm 0.1$ & $6.29 \pm 0.1$ & - \\
\hline 800/10-per & $6.27 \pm 0.1$ & $6.28 \pm 0.0$ & $6.27 \pm 0.0$ & $6.27 \pm 0.1$ & - \\
\hline 800/5-per & $6.27 \pm 0.0$ & $6.27 \pm 0.1$ & $6.28 \pm 0.0$ & $6.27 \pm 0.1$ & - \\
\hline 30 kD-ret & $6.28 \pm 0.1$ & $6.27 \pm 0.2$ & $6.28 \pm 0.1$ & $6.28 \pm 0.1$ & - \\
\hline 30/10-per & $6.29 \pm 0.0$ & $6.27 \pm 0.0$ & $6.27 \pm 0.1$ & $6.27 \pm 0.0$ & - \\
\hline 30/5-per & $6.27 \pm 0.1$ & $6.28 \pm 0.0$ & $6.28 \pm 0.1$ & $6.27 \pm 0.0$ & - \\
\hline IFA & $6.30 \pm 0.1$ & $6.29 \pm 0.1$ & $6.27 \pm 0.2$ & $6.28 \pm 0.1$ & - \\
\hline
\end{tabular}

a Jenness (1980); HM: Human milk; 800 kD-ret: 800 kDa retentate fraction; 800/30-per: 800/30 kDa permeate fraction; 800/10-per: 800/10 kDa permeate fraction; 800/5-per: 800/5 kDa permeate fraction; 30 kd-ret: $30 \mathrm{kDa}$ retentate fraction; 30/10-per: 30/10 kDa permeate fraction; 30/5-per: 30/5 kDa permeate fraction; IFA: Infant formula analog; RGM: raw, refrigerated goat milk; FGM: raw, frozen goat milk; PGM: pasteurized, refrigerated goat milk; PFGM: pasteurized, frozen goat milk.

difference in $\mathrm{pH}$ values among all milk fractions (Table 2). The infant formula analogs had $\mathrm{pH}$ values comparable to that of human milk. Temperature treatments and protein fraction therefore had no effect on the $\mathrm{pH}$ of the base milk, milk fractions and infant formula analogs.

\subsection{Effect of Temperature Treatment}

Temperature treatment appeared to have a great effect on the separation efficiency of the caprine milk proteins. RGM showed a concentration of the major whey proteins $(\beta$-Lg and $\alpha$-La) in the $800 \mathrm{kDa}$ retentate fraction (Figure 1). Approximately $70 \%$ of the total components in this fraction comprised of $\beta$-Lg and $\alpha$-La, while these proteins were not detected in the rest of the fractions for this milk sample. This might be as a result of the $\mathrm{pH}$ dependency and ionic attraction of the natural caprine milk proteins in the normal milk system, which enables an increase in their virtual size by surrounding ionic cloud [17], and renders their separation difficult with membranes of molecular size cut-off of $30 \mathrm{kDa}$ and below.

However, heat treatment of the milk prior to ultrafiltration of PGM appeared to give milk fractions with major whey protein contents comparable to that of RGM (Figures 1 and 2). Although heat treatment is known to cause denaturation of milk proteins to an extent, tempering of the milk at refrigeration temperatures also allows for refolding and renaturation of these milk proteins, whereby they tend to retain their normal form [19]. Most of the major whey proteins in PGM are concentrated in the $800 \mathrm{kDa}$ retentate fraction, as in RGM, with very little or none of these proteins detected in the rest of the milk fractions (Figures 1 and 2).

FGM, on the other hand, showed a greater distribution of the major whey proteins in the $800 \mathrm{kDa}(34 \%)$, and 30 $\mathrm{kDa}(22 \%)$ retentate and $800 / 30 \mathrm{kDa}(32 \%)$ permeate fractions, with about $87 \%, 60 \%$ and $30 \%$ of the respective proteins attributable to $\beta$-Lg. This sample also showed the presence of major whey proteins in the 800/10, 800/5, $30 / 10$ and $30 / 5$ permeates. It, therefore, follows that the different behavior of the proteins in FGM during ultrafiltration, compared with RGM, can be as a result of the freezing treatment of FGM. This has probably resulted in a more hydrated and flexible structure of the protein molecules [19], thereby allowing permeation of these proteins through the $30 \mathrm{kDa}$ membrane pores.

The combined high temperature and freezing treatment of caprine milk (PFGM) appeared to result in denaturation of the milk proteins, and the resulting behavior of these proteins during subsequent ultrafiltration is comparable to that of FGM. The milk fractions of the PFGM sample had the highest major whey protein concentration in the $800 \mathrm{kDa}(36 \%)$, and $30 \mathrm{kDa}(20 \%)$ retentates, and 800/30 kDa (37\%) permeate. Although $\beta$-Lg accounted for about $86 \%$ and $57 \%$ of the respective major whey protein values in the retentate fractions, its level in the permeate fraction was significantly lower (18\%), and it was not detected in the other permeate fractions of this PFGM sample. 


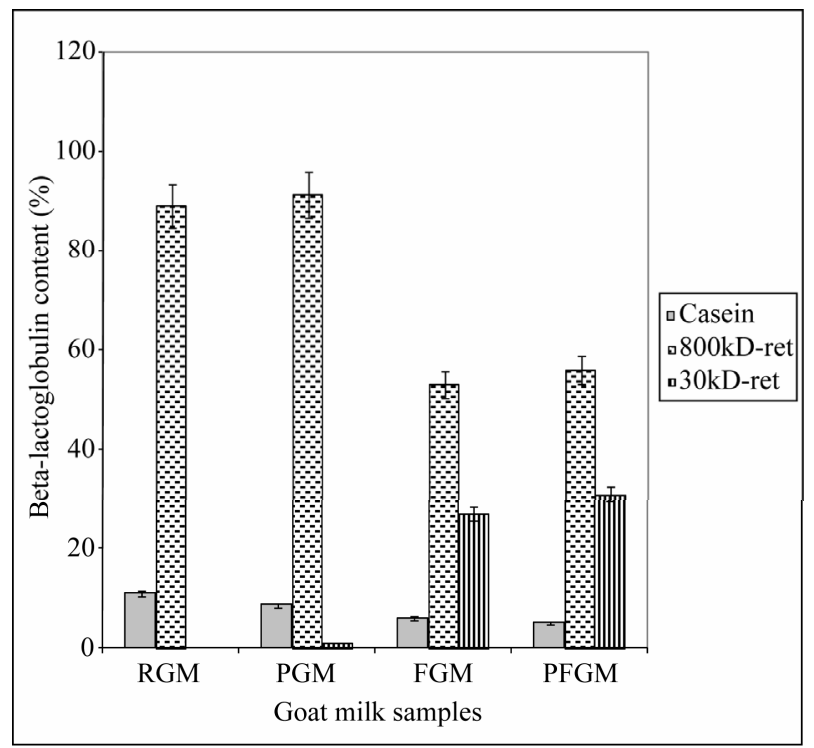

Figure 1. Percentage $\beta$-lactoglobulin in the retentate fractions. $800 \mathrm{kD}$-ret: $800 \mathrm{kDa}$ retentate fraction; $30 \mathrm{kD}$-ret: 30 kDa retentate fraction; RGM: raw, refrigerated goat milk; FGM: raw, frozen goat milk; PGM: pasteurized, refrigerated goat milk; PFGM: pasteurized, frozen goat milk. Sample number $(n)=6$. Error bars indicate standard deviation (mean \pm standard deviation).

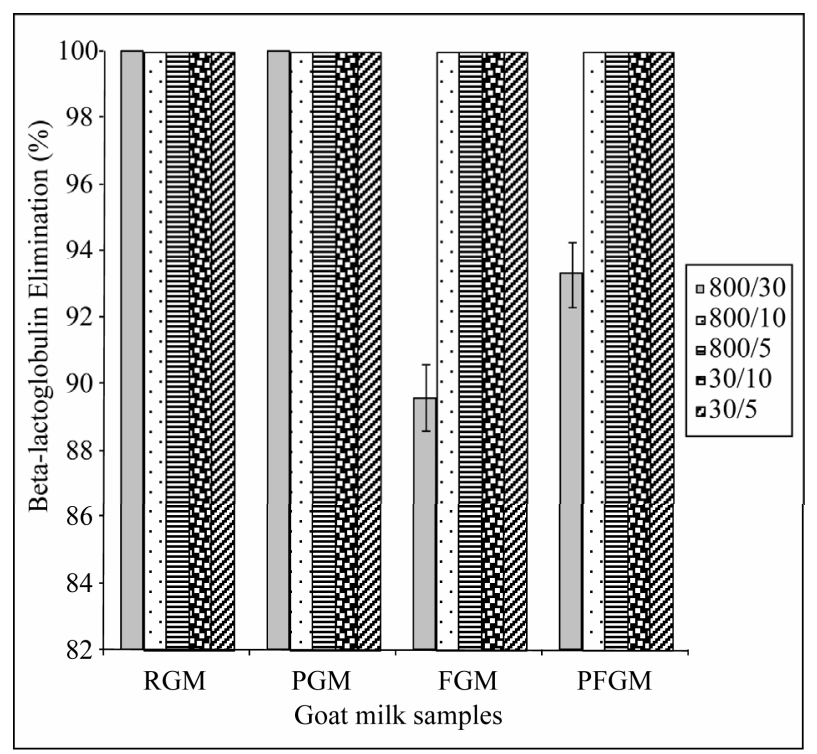

Figure 2. Percentage $\beta$-lactoglobulin elimination in the permeate fractions. 800/30-per: 800/30 kDa permeate fraction; 800/10-per: 800/10 kDa permeate fraction; 800/5-per: 800/5 kDa permeate fraction; 30/10-per: $30 / 10$ kDa permeate fraction; 30/5-per: 30/5 kDa permeate fraction; RGM: raw, refrigerated goat milk; FGM: raw, frozen goat milk; PGM: pasteurized, refrigerated goat milk; PFGM: pasteurized, frozen goat milk. Sample number $(n)=6$. Error bars indicate standard deviation (mean \pm standard deviation).
The four temperature treated milk samples showed the presence of residual whey proteins in the casein fraction, which accounted for about $15 \%-23 \%$ of the total major whey proteins. This is expected since some of the whey proteins would always be present in the concentrated casein fraction, when using membrane separation techniques [17,21]. Higher levels $(18 \%-23 \%)$ of these residual whey proteins were detected in RGM and PGM casein fractions than that of FGM and PFGM. These higher levels of residual major whey proteins in the caseins of the non-frozen milk samples may be as a result of the native whey protein dependency on the fluid milk system $[17,19]$, which makes it more difficult to separate from the milk caseins. On the other hand, the residual whey proteins in FGM were comparable to that of PFGM. The lower residual whey protein content in the casein fraction of these milk samples can be attributable to relaxation of the natural rigidity of the proteins caused by the heat and/or subsequent freezing treatment of these samples [19].

\subsection{Comparison of Membrane Performance}

\subsubsection{Elimination of $\boldsymbol{\beta}$ - $\mathrm{Lg}$}

The percentages elimination of $\beta$-Lg from the permeate fractions of the temperature treated milk samples are shown in Figure 2. There appeared to be a complete elimination of $\beta$ - Lg from most of the permeate fractions of all four treated milk groups. Although the $800 / 30 \mathrm{kDa}$ permeate fractions of FGM and PFGM groups showed a slightly lower level of elimination of $\beta$-Lg (90 and 93.8\%) in comparison to those of other milk groups (Figure 2), differences were not statistically significant $(P>0.05)$ in the percentage elimination of this protein among the permeates obtained from the different membrane sizes. The high efficiency of $\beta$-Lg elimination from the permeates of the second-step ultrafiltration fractionation of the four milk groups can be attributed to the ability of $\beta$ - $\mathrm{Lg}$ to form a bipolymer in the absence of casein particles and presence of $\alpha$-La, around normal milk pH [17]. This bipolymer formation of $\beta$ - Lg in whey fractions can increase its molecular size, whereby its complete elimination occurred from the permeate fractions of membrane pore sizes of $10 \mathrm{kDa}$ or less (Figure 2). A nearly complete elimination was also observed from that of $30 \mathrm{kDa}$ membrane pore size (Figure 2). Furthermore, pasteurization prior to freezing appeared to affect the efficiency of $\beta$-Lg elimination from milk whey. This is apparent from the higher (4\%) elimination of $\beta$ - $\mathrm{Lg}$ in the $800 / 30 \mathrm{kDa}$ permeate of PFGM in comparison with FGM (Figure 2). This might have been a result of the freezing by intensifying the degree of protein denaturation that occurred during pasteurization of the PFGM samples prior to 
membrane separation [19]. Therefore, this situation caused a greater attraction of the unfolded $\beta$-Lg molecules to form bipolymers [17], thus further preventing their passage through the second-step $30 \mathrm{kDa}$ membrane pores.

\subsubsection{Retention of $\alpha$-La}

The complete removal of $\beta$-Lg from caprine milk whey by membrane filtration is highly desirable for infant formula production. However, the retention of other whey proteins, especially $\alpha$-La, is crucial in the determination of suitable membrane pore sizes for caprine milk fractionation. The percentage retention of $\alpha$-La in the different permeate fractions for the four milk samples are presented in Figure 3. The 800/5, 30/10, and 30/5 kDa permeates of RGM and PGM showed little or no detectable $\alpha$-La (Figure 3). This inability of $\alpha$-La to permeate the pore sizes of 5 and $10 \mathrm{kDa}$ membranes during the second-step fractionation of RGM and PGM can be attributable to its molecular size $(14 \mathrm{kDa})$ in its natural state, which is bigger than the membrane pore size. The charged nature of the protein also enables it to attract electrons to itself, thereby resulting in an increase in its virtual molecular size $[17,22]$, and further prevent permeation through the membrane pores. The similarity of the $\alpha$-La retention in the permeate fractions of PGM to RGM is likely due to the complete or partial refolding of

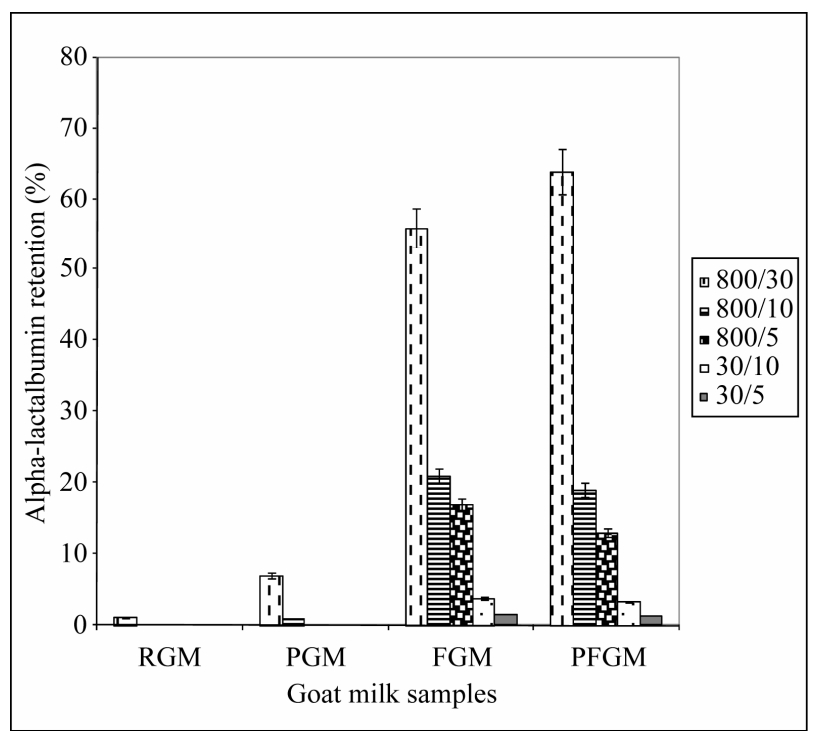

Figure 3. Percentage $\alpha$-lactalbumin retention in the permeate fractions. 800/30-per: $800 / 30 \mathrm{kDa}$ permeate fraction; 800/10-per: 800/10 kDa permeate fraction; 800/5-per: 800/5 kDa permeate fraction; 30/10-per: $30 / 10 \mathrm{kDa}$ permeate fraction; 30/5-per: 30/5 kDa permeate fraction; RGM: raw, refrigerated goat milk; FGM: raw, frozen goat milk; PGM: pasteurized, refrigerated goat milk; PFGM: pasteurized, frozen goat milk. Sample number $(n)=6$. Error bars indicate standard deviation (mean \pm standard deviation). this protein during tempering in refrigeration to their natural form. These results are similar to that reported by Erdem and Yuksel [19], where the whey proteins heatdenatured, returned to their original state during refrigerated storage.

The FGM and PFGM milk samples, on the other hand, showed significant retention of $\alpha$-La in all permeate fractions (Figure 3). These higher levels of $\alpha$-La in the permeate fractions of FGM and PFGM, unlike their nonfrozen counterparts, therefore show that freezing of caprine milk had a positive effect on the retention of $\alpha$-La in the different permeate fractions. The 800/30 kDa permeate fraction of both FGM and PFGM milk groups contained the highest $\alpha$-La level, which is up to $62 \%$ higher than that of the other permeate fractions (Figure 3). This shows that the membrane pore size had a significant effect on the degree of retention of $\alpha$-La in the permeate fractions. These high levels of $\alpha$-La in this fraction can be largely accounted for the molecular size of this protein $(14 \mathrm{kDa})$ which enables easy permeation through the $30 \mathrm{kDa}$ membrane and a restricted permeation through the 10 and $5 \mathrm{kDa}$ membranes.

\subsection{Comparison of Protein Composition among Formula Analogues, Human and Caprine Milk}

The 800/30 kDa-permeate was chosen as the optimum permeate fraction due to the higher level of $\beta$-Lg elimination and $\alpha$-La retention obtained than in the other permeate fractions. This optimum whey permeate was therefore used for the preparation of the caprine milk infant formula analogs.

The total protein contents of the infant formula analogs are compared with those of previously reported caprine milk and human milk in Table 3. The infant formula analogs had lower protein contents than caprine milk, due mainly to their reduced whey protein content as a result of whey protein reduction during the fractionation processes, and the dilution of the caseins with the whey permeate during preparation. RGM and PGM formula analogs had the lowest total protein content, while reported normal caprine milk had the highest (Table 3). There were no differences between the protein contents of RGM and PGM, and between those of FGM and PFGM. Human milk has a total protein content about $60 \%$ lower than that of normal caprine milk. Likewise, infant formula analogs prepared with RGM and PGM showed a lower protein content than the other formula analogs; with up to $50 \%$ lower total protein in both infant formula analogs than in FGM and PFGM infant formula analogs (Table 3). The lower total protein content of RGM and PGM formula analogs can be directly related to the 
Table 3. Comparison of protein compositions among the experimental infant formula analogs, goat milk and human milk.

\begin{tabular}{|c|c|c|c|c|c|c|}
\hline & \multicolumn{6}{|c|}{ IFAs containing four milk groups ${ }^{\mathrm{a}}$} \\
\hline & RGM & PGM & FGM & PFGM & $\mathrm{GM}^{\mathrm{b}}$ & $\mathrm{HM}^{\mathrm{c}}$ \\
\hline Total protein (mg/100g) & $0.74 \pm 0.23$ & $0.71 \pm 0.14$ & $1.52 \pm 0.13$ & $1.41 \pm 0.12$ & 3.3 & 1.3 \\
\hline Whey protein (mg/100g) & $0.22 \pm 0.03$ & $0.14 \pm 0.04$ & $0.92 \pm 0.10$ & $0.81 \pm 0.12$ & 0.6 & 0.8 \\
\hline$\beta$-Lg (\%) & $2.91 \pm 0.30$ & $1.74 \pm 0.13$ & $2.00 \pm 0.21$ & $1.23 \pm 0.20$ & 21.8 & - \\
\hline Casein: whey protein ratio & $3.71 \pm 0.11$ & $4.10 \pm 0.12$ & $0.62 \pm 0.03$ & $0.68 \pm 0.11$ & $3.0-6.7$ & $0.4-0.7$ \\
\hline
\end{tabular}

${ }^{a}$ All IFAs (infant formula analogues) were prepared by combining 1 part of the diluted casein fraction and 4 parts of the corresponding optimum permeate fractions $\left(\mathrm{v}^{\cdot} \mathrm{v}^{-1}\right)$ of each treated goat milk group (The 800/30 kDa-permeate fractions were chosen to formulate all formula analogues, because this membrane combination had the best results for $\beta$-Lg elimination and $\alpha$-La retention); ${ }^{b}$ Park and Haenlein (2006); GM: goat milk; ' ${ }^{\circ}$ enness (1980); HM: human milk; The abbreviations for RGM, FGM, PGM, and PFGM are same as those in Table 2.

lower whey protein content of their starting permeate material, which therefore reduced the total protein content of these milk analog groups. FGM and PFGM infant formula analogs, on the other hand, showed a reduced total protein content that is lower than that of reported whole caprine milk, but similar to human milk (Table 3).

The whey protein content of FGM and PFGM infant formula analogs also were higher (25\%) than that of documented caprine milk, but closer to that of human milk (Table 3). RGM and PGM formula analogs had the lowest whey protein content, about $75 \%$ lower than that of FGM and PFGM infant formula analogs (Table 3). The low whey protein content of both infant formula analogs can be attributed to the lower whey protein content of their starting material.

The amount of $\beta$-Lg accounts for about one-fifth of the total protein in caprine milk [3], but this protein is absent from human milk [23]. The presence of $\beta$-Lg in the infant formula analogs $(1 \%-2 \%)$ is as a result of the retention of this protein in the casein fraction of the milk samples. Although the differences in the $\beta$-Lg content among the infant formula analogs may not be statistically significant $(P>0.05)$, the RGM analog had the highest $\beta$-Lg content, whereas the PFGM analog had the lowest, followed by the PGM analog (Table 3).

The ratios of casein to whey protein of the infant formula analogs are compared with those of the reported caprine milk and human milk in Table 3 . The caseinlactalbumin ratios of RGM and PGM appeared similar to that of the reported caprine milk, while these indices for FGM and PFGM were significantly lower and comparable to that of human milk (Table 3). The higher values of this index in RGM and PGM infant formula analogs are as a result of the low $\alpha$-La content of these milk groups, unlike FGM and PFGM. The results in Table 3 therefore indicate that the FGM and PFGM infant formula analogs had the closest similarity to the protein composition of human milk.

\section{Conclusions}

Caprine milk protein was successfully fractionated by ultrafiltration to reduce the protein content and eliminate $\beta$-lactoglobulin, to help simulate the protein composition to human milk. Temperature treatment of the milk can cause partial denaturation of goat milk proteins, which improves membrane performance during fractionation. The caprine milk infant formula analogs produced showed a similarity to human milk with respect to the total protein content, $\beta$-lactoglobulin content, and casein-lactalbumin ratio, indicating that humanizing the caprine milk proteins is feasible for development of caprine milk infant formulas for feeding infants who need alternative milk, especially those who have bovine milk allergy.

\section{Acknowledgements}

This research was supported by the USDA 1890 Capacity Building grant No. 2001-38814-11388. The authors thank Mr. Schauston Miller for collection of goat milk samples for this study.

\section{REFERENCES}

[1] A. H. Rosenblum and P. Rosenblum, "Gastrointestinal Allergy in Infancy: Significance of Eosinophiles in the Stools,” Pediatrics, Vol. 9, No. 3, 1952, pp. 311-319.

[2] Y. W. Park, "Hypo-Allergenic and Therapeutic Significance of Goat Milk,” Small Ruminant Research Journal, Vol. 14, No. 2, 1994, pp. 151-159. doi:10.1016/0921-4488(94)90105-8

[3] Y. W. Park and G. F. W. Haenlein, "Therapeutic and Hypoallergenic Values of Goat Milk and Implication of Food Allergy,” In: Y. W. Park and G. F. W. Haenlein, Eds., Handbook of Milk of Nonbovine Mammals, Blackwell Publishing Professional, Oxford, 2006, pp. 121-136.

[4] L. S. Taitz and B. L. Armitage, “Goat's Milk for Infants and Children,” British Medical Journal, Vol. 288, 1984, pp. 428-429. doi:10.1136/bmj.288.6415.428

[5] J. A. Birkbeck, "Goat Milk in Infant Feeding," New 
Zealand Medical Journal, Vol. 87, 1978, pp. 365-369.

[6] P. Kirke, "Human Consumption of Goat's Milk," International Medical Journal, Vol. 72, 1979, pp. 492-498.

[7] V. B. Walker, "Therapeutic Uses of Goat Milk in Modern Medicine,” British Goat Society’s Yearbook 24 - 26, 1965, pp. 23-26.

[8] G. F. W. Haenlein and R. Caccese, "Goat Milk versus Cow Milk,” In: G. F. W. Haenlin and D. L. Ace, Eds., Extension Goat Handbook, USDA Publication, Washington DC, 1984, pp. 1-4.

[9] Y. W. Park and H. I. Chukwu, "Macro-Mineral Concentrations in Milk of Two Goat Breeds at Different Stages of Lactation,” Small Ruminant Research Journal, Vol. 1, No. 2, 1988, pp. 157-166. doi:10.1016/0921-4488(88)90032-6

[10] Y. W. Park, "Relative Buffering Capacity of Goat Milk, Cow Milk, Soy-Based Infant Formulas, and Commercial Non-Prescription Antacid Drugs,” Journal of Dairy Science, Vol. 74, No. 10, 1991, pp. 3326-3333. doi:10.3168/jds.S0022-0302(91)78520-2

[11] S. L. Bahner and D. C. Heiner, "Allergies to Milk," Grune and Stratton Publishing, New York, 1980.

[12] M. Heyman and J. F. Desjeux, "Significance of Intestinal Food Protein Transport," Journal of Pediatric, Gastroenterology, Nutrition, Vol. 15, No. 1, 1992, pp. 48-57. doi:10.1097/00005176-199207000-00008

[13] Y. W. Park, “Goat Milk-Chemistry and Nutrition,” In: Y. W. Park and G. F. W. Haenlein, Eds., Handbook of Milk of Nonbovine Mammals, Blackwell Publishing Professional, Oxford, 2006, pp. 34-58.

[14] S. Parkash and R. Jenness, "The Composition and Characteristics of Goat's Milk: A Review,” Dairy Science Abstract, Vol. 30, 1968, p. 67.

[15] R. Jenness, "Composition and Characteristics of Goat Milk: Review 1968-1979,” Journal of Dairy Science, Vol.
63, No. 10, 1980, pp. 1605-1630. doi:10.3168/jds.S0022-0302(80)83125-0

[16] R. J. Pearce, "Whey Protein Recovery and Whey Protein Fractionation,” In: J. G. Zadow, Ed., Whey and Lactose Processing, Elsevier Applied Science, New York, 1992, pp. 271-316. doi:10.1007/978-94-011-2894-0 8

[17] A. L. Zydney, "Protein Separations Using Membrane Filtration: New Opportunities for Whey Fractionation," International Dairy Journal, Vol. 8, No. 3, 1998, pp. 243250. doi:10.1016/S0958-6946(98)00045-4

[18] T. Kuwata, A. M. Pham, C. Y. Ma and S. Nakai, "Elimination of $\beta$-Lactoglobulin from Whey to Simulate Human Milk Protein,” Journal of Food Science, Vol. 50, No. 3, 1985, pp. 605-609. doi:10.1111/j.1365-2621.1985.tb13755.x

[19] Y. K. Erdem and Z. Yuksel, "Sieving Effect of Heat Denatured Milk Proteins during Ultrafiltration of Skim Milk. I. The Preliminary Approach," Journal of Dairy Science, Vol. 88, No. 6, 2005, pp. 1941-1946. doi:10.3168/jds.S0022-0302(05)72869-1

[20] SAS, “The SAS Program for Windows,” SAS Institute, Cary, 1996.

[21] G. Brans, C. G. P. H. Schroen, R. G. M. van der Sman and R. M. Boom, "Membrane Fractionation of Milk: State of the Art and Challenges," Journal of Membrane Science, Vol. 243, No. 1-2, 2004, pp. 263-272. doi:10.1016/j.memsci.2004.06.029

[22] A. Tolkach and U. Kulozik, "Fractionation of Whey Proteins and Caseinomacropeptide by Means of Enzyme Crosslinking and Membrane Separation Techniques," Journal of Food Engineering, Vol. 67, No. 1-2, 2005, pp. 13-20. doi:10.1016/j.jfoodeng.2004.05.058

[23] J. Morgan, “Human Milk,” In: Y. W. Park and G. F. W. Haenlein, Eds., Handbook of Milk of Nonbovine Mammals, Blackwell Publishing Professional, Oxford, 2006, pp. 407-420. doi:10.1002/9780470999738.ch18 